\title{
Correction to: Proteomics analysis of the germinating seeds of Cariniana legalis (Mart.) Kuntze (Meliaceae): an endangered species of the Brazilian Atlantic Rainforest
}

\author{
Bianca Machado Campos Trindade ${ }^{1,2} \cdot$ Ricardo Souza Reis $^{1,2} \cdot$ Ellen Moura Vale ${ }^{1,2} \cdot$ Claudete Santa-Catarina $^{3}$. \\ Vanildo Silveira ${ }^{1,2}$ (1)
}

Published online: 9 January 2018

(C) Botanical Society of Sao Paulo 2018

\section{Correction to: Braz. J. Bot}

https://doi.org/10.1007/s40415-017-0419-7

In the original publication of this article, the title is incorrect. The correct title should be: Proteomics analysis of the germinating seeds of Cariniana legalis (Mart.) Kuntze (Lecythidaceae): an endangered species of the Brazilian Atlantic Rainforest.

The authors apologize for the inconvenience caused.

The original article can be found online at https://doi.org/10.1007/s40415-017-0419-7.

Vanildo Silveira

vanildo@uenf.br

1 Laboratório de Biotecnologia, Centro de Biociências e Biotecnologia (CBB), Universidade Estadual do Norte Fluminense Darcy Ribeiro (UENF), Campos dos Goytacazes, RJ 28013-602, Brazil

2 Unidade de Biologia Integrativa, Setor de Genômica e Proteômica, UENF, Campos dos Goytacazes, RJ 28013-602, Brazil

3 Laboratório de Biologia Celular e Tecidual, CBB, UENF, Campos dos Goytacazes, RJ, Brazil 